\title{
INFLUENZA IN HOSPITAL 1960-1961
}

\author{
G. W. Hearn, M.B.E., M.D., M.R.C.P. \\ Physician, Dudley Road Hospital, Birmingham
}

DURING most winters the regional hospitals in Birmingham have become accustomed to receive an embarrassing number of acute respiratory disorders as emergency admissions. The clinical and epidemiological features of these periodic surges of respiratory disease posed problems of interest and difficulty. Precise classification of individual cases might be a matter of conjecture. In patients showing close clinical similarity several different kinds of bacteria might be cultured, often more than one concurrently or serially in the same case, or none might be obtained. Radiological appearances varied widely. An increase in the number of these apparently different respiratory cases at the same time, however, suggested common factors. The influenza virus was known to be one of these factors. It therefore seemed desirable to investigate the range and frequency of clinical phenomena observed in hospital admissions during an epidemic and to relate these clinical studies to the evidence of virus infection.

An epidemic of influenza $\mathrm{A}_{2}$ in Birmingham in late December 1960 was therefore studied. The onset of the epidemic was rapid; this led to prompt recognition of the epidemic situation and early identification of the virus responsible. It was therefore possible to undertake a clinical and virological study of all the respiratory admissions to a medical unit at Dudley Road Hospital during the course of the epidemic, the virological study being undertaken by Dr. Flewett. Non-respiratory cases were included in the study where influenza appeared a possible cause. To present the range of clinical cases observed and to relate them to evidence of virus infection is the purpose of this paper.

\section{Epidemiology}

During the last weeks of 1960 there had been no prevalence of febrile disorders and no influenza had been reported in the British Isles. The existence of complicated influenza became apparent on December 26, 1960, after the admission of two patients with fulminating staphylococcal pneumonia and three patients with influenzal bronchopneumonia. Thereafter the number of admissions for acute respiratory disorders rose sharply and remained high until the end of January

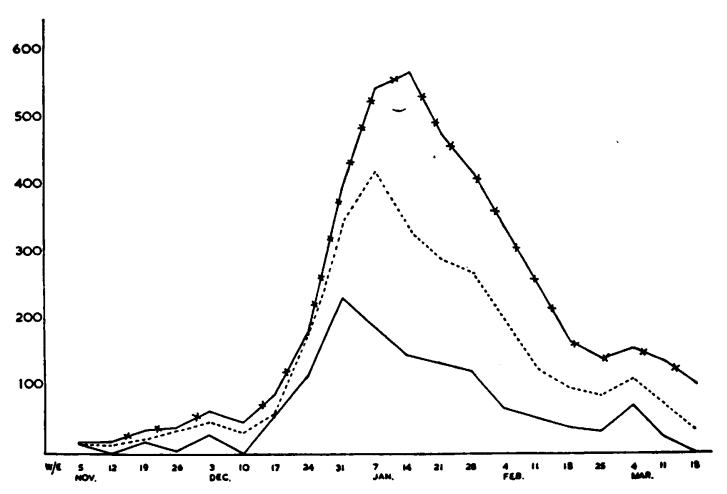

Fig. 1.-Birmingham Bed Bureau, November I960 to March I96I (see text).

I96r. The progress of the epidemic was conveniently delineated by the rise and fall in emergency admissions to Birmingham hospitals through the Birmingham Emergency Bed Bureau.

In I960 the average weekly admissions were 250. Fig. I shows the weekly admissions in excess of this figure during the epidemic and charts the additional beds needed on the assumption of a two-week and three-week stay.

During the winter of 1960-6r the Emergency Bed Bureau did not return respiratory admission statistics separately, but did so subsequently. During the next winter it was therefore possible to demonstrate in a similar epidemic that the increase in admissions during the epidemic period was almost entirely due to the respiratory disorders (Fig. 2).

\section{Virology}

In all, I03 patients were included in this study. The intention was to take paired sera in all cases for complement fixation studies; this was frustrated by some early deaths and some practical difficulties but at least one serum was obtained from each of 90 patients and on these complement fixation studies were performed by Dr. Flewett and are reported here. His culture of autopsy material and hæmagglutination inhibition studies confirmed that the epidemic was due to influenza A2. 


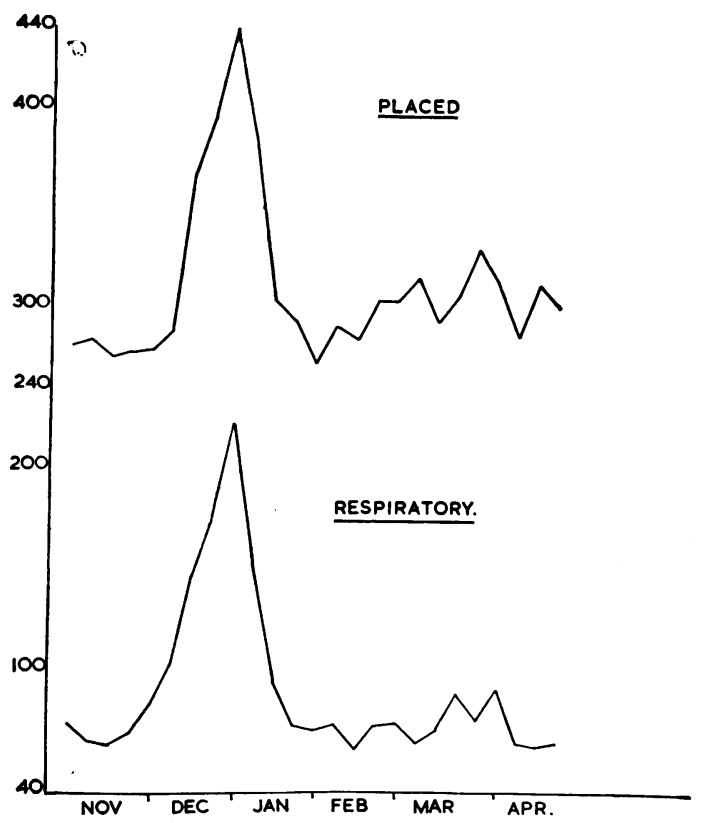

Fig. 2.-Bed Bureau cases (see text).

Since in some cases one serum only was obtained, and since most cases were admitted 7-I4 days after onset, it was not always practicable to use a fourfold rise in titre as a criterion of infection. The criterion of Stuart Harris (1953) was accepted, that a titre of $I: I 6$ or more in a single specimen was an index of recent infection After January 31 , 1961 , the number of admis sions and the severity of the respiratory illnesses declined, and of the sera studied from I 5 patients admitted after that date I $3_{3}$ were negative and $\overrightarrow{3}$ gave a positive complement fixation at a titre of I : 6 only. This confirmed the clinical impressiof that the epidemic had largely disappeared by the end of January. If these 15 negative or low tit sera from patients admitted after January 3 f are excluded, from the remaining 75 sera comples ment fixation titres with influenza $A$ solubte antigen of $I: 16$ or more were obtained in $52(69 \%$ Stuart Harris (I953) reported positive complemerse fixation studies in $70 \%$ of hospital admissions for complicated influenza in the Influenza epidemic of $195 \mathrm{I}$, and Clarke, Heath, Suttor. and Stuart-Harris (1958) reported similar findings in $74 \%$ in the 1957 epidemic of Influenza A 27 The approximation of the present figures suggests that the great majority of these cases here reported were in fact due to influenza A2. This conclusion is confirmed by the finding of high complement fixation titres only during the epidemic period (Table r). The distribution of complement fix of tion titres in relation to age appears in Table 2 .

\section{Clinical Studies}

The diagnoses of patients in which serw studies were obtained are classified in Table 3 under these classifications the principal clinic features are considered.

TABLE I

Weekly Complement Fixation Titres Related to Numbers of Emergency Admissions

\begin{tabular}{|c|c|c|c|c|c|c|c|c|c|c|}
\hline Week Ending: & $\begin{array}{c}\text { Dec. } \\
\text { ro }\end{array}$ & $\begin{array}{l}\text { Dec. } \\
\text { I } 7\end{array}$ & $\begin{array}{c}\text { Dec. } \\
24\end{array}$ & $\begin{array}{l}\text { Dec. } \\
\text { 3I }\end{array}$ & $\underset{7}{\mathrm{Jan}}$ & $\underset{14}{\text { Jan. }}$ & $\underset{21}{J}$ & $\begin{array}{l}\text { Jan. } \\
28\end{array}$ & $\begin{array}{c}\text { Feb. } \\
4\end{array}$ & Feb. \\
\hline $\begin{array}{l}\text { Titre reciprocal: } \\
32 \text { and above }\end{array}$ & - & - & 2 & I0 & 8 & 9 & 2 & 6 & - & \\
\hline Below 32 & - & - & I & 8 & 8 & Io & 3 & 8 & 9 & \\
\hline $\begin{array}{l}\text { Cases placed by Bed Bureau } \\
\text { Respiratory cases, Bed }\end{array}$ & 260 & 319 & 377 & 487 & 435 & 406 & 396 & 377 & 347 & \\
\hline Bureau $\ldots \quad \ldots$ & 79 & 96 & 153 & 245 & 200 & 173 & I4I & I 34 & 88 & \\
\hline
\end{tabular}

TABLE 2

Complement Fixation Studies-Age Distribution

\begin{tabular}{rl|c|c|c|c|c|c|c|c}
\hline & & $10-19$ & $20-29$ & $30-39$ & $40-49$ & $50-59$ & $60-69$ & $70-79$ & $80+$ \\
\hline 128 & $\cdots$ & - & 2 & - & 2 & 7 & 6 & 5 & 2 \\
64 & $\cdots$ & - & - & - & 3 & 1 & 1 & 2 & - \\
32 & $\cdots$ & - & - & 1 & - & 1 & 3 & 2 & - \\
16 & $\cdots$ & - & 1 & 1 & 2 & 1 & 7 & 2 & 1 \\
8 & $\cdots$ & - & - & 2 & - & - & 2 & 7 & 2 \\
0 & $\cdots$ & 1 & - & 2 & 3 & 7 & 10 & 6 & 2 \\
\hline
\end{tabular}


TABLE 3

Diagnoses of Cases Checked by Complement Fixation, 1960-6i

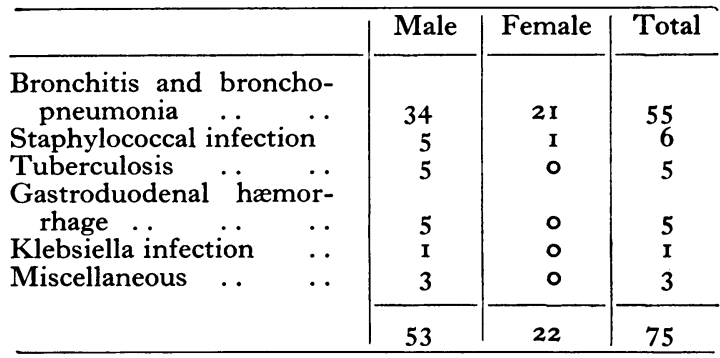

TABle 4

Complement Fixation Studies in Bronchitis AND BRONCHOPNEUMONIA, I 960-6I

\begin{tabular}{|c|c|c|c|c|c|}
\hline \multicolumn{3}{|c|}{ C.F. Reciprocal } & Male & Female & Total \\
\hline 128 & . & .. & 10 & 8 & 18 \\
\hline 64 & .. & . & 4 & I & 5 \\
\hline 32 & .. & .. & 3 & I & 4 \\
\hline 16 & .. & .. & 8 & 3 & I I \\
\hline 8 & . & . & I & 2 & 3 \\
\hline o & . & .. & 8 & 6 & 14 \\
\hline & otal & .. & 34 & 21 & 55 \\
\hline
\end{tabular}

I 6 and above $=38(70 \%)$

\section{Bronchitis and Bronchopneumonia}

This diagnostic category included 55 patients, 34 males and 21 females; Table 4 records the titre reciprocals, a titre of $\mathrm{I}: \mathrm{I} 6$ or more being obtained in $70 \%$. Table 5 indicates the age distribution by sexes and notes the deaths and the frequency of previous respiratory disease in the history.

The notable features are the concentration of cases among the more elderly, the restriction of mortality to those over 60 years, and the frequency in all age groups of previous respiratory disease.

The clinical features were those previously described as occurring in influenza A (Stuart-
Harris, 1953) and no detailed analysis is necessary here. Most, but not all, patients gave a history of an influenzal illness at onset with cough, malaise, headache and aching in the limbs. Substernal pain on coughing was frequent, and in a smaller number of patients vomiting occurred during the first two days of the disease. Admissions occurred from 3 to 20 days after onset and were usually the result of continuation or relapse of fever, and progressive respiratory deficiency. The clinical appearances on admission were usually those of acute obstructive lung disease due to bronchiolitis or bronchopneumonia; the contribution to this appearance made by pre-existing chronic obstructive lung disease was sometimes over-estimated during the acute stage. Most patients were febrile on admission. Cyanosis was frequent and often gross. Congestive failure due to cor pulmonale or auricular fibrillation was observed and acute confusional states were a common final cause of admission.

The classical distinction as between influenzal and post-influenzal was frequently difficult, and it is doubtful whether this distinction serves any useful purpose. In some patients the history suggested a biphasic disease.

The distinction between bronchitis, bronchiolitis and bronchopneumonia could not be clearly made. Even in those patients showing extensive radiological changes there was rarely any alteration in breath sounds. Bilateral diffuse rales were so frequent as to be the principal diagnostic feature.

It is not the purpose of this paper to discuss treatment but it is worthy of note that tracheostomy was employed in two patients only, both of whom died.

\section{Staphylococcal Infection}

Complement fixation studies were carried out in 6 patients in whom staphylococcal infection

TABLE 5

Bronchitis and Bronchopneumonia-Age Distribution

\begin{tabular}{|c|c|c|c|c|c|c|c|c|c|}
\hline \multicolumn{2}{|c|}{$\begin{array}{l}\text { Age } \\
\text { Groups }\end{array}$} & \multicolumn{4}{|c|}{ Male } & \multicolumn{4}{|c|}{ Female } \\
\hline $\begin{array}{l}20-29 \\
30-39 \\
40-49 \\
50-59 \\
60-69 \\
70-79 \\
80\end{array}$ & $\begin{array}{l}\ldots \\
\cdots \\
\cdots \\
\cdots \\
\cdots\end{array}$ & $\begin{array}{l}1 \\
- \\
4 \\
9 \\
9 \\
7 \\
4\end{array}$ & $\begin{array}{l}- \\
- \\
2 \\
7 \\
7 \\
3 \\
2\end{array}$ & $\begin{array}{l}\mathbf{I} \\
- \\
- \\
- \\
- \\
-\end{array}$ & $\begin{array}{l}0 \\
0 \\
0 \\
0 \\
3 \\
2 \\
2\end{array}$ & $\begin{array}{l}- \\
1 \\
2 \\
2 \\
8 \\
5 \\
3\end{array}$ & $\begin{array}{l}- \\
\text { I } \\
\text { I } \\
1 \\
5 \\
3 \\
-\end{array}$ & $\begin{array}{l}- \\
- \\
- \\
- \\
- \\
-\end{array}$ & $\begin{array}{l}- \\
0 \\
0 \\
0 \\
2 \\
1 \\
1\end{array}$ \\
\hline Total & $\ldots$ & 34 & $21(60 \%)$ & $\mathbf{I}$ & $7(20 \%)$ & 21 & II $(55 \%)$ & - & $4(20 \%)$ \\
\hline
\end{tabular}


TABLE 6

Staphylococcal Infections During Influenza Epidemic

\begin{tabular}{|c|c|c|c|c|c|c|}
\hline & Case & Age & Diagnosis & $\begin{array}{l}\text { C.F. } \\
\text { Titre }\end{array}$ & $\begin{array}{c}\text { Duration } \\
\text { of Stay } \\
\text { (Days) }\end{array}$ & Result \\
\hline $\begin{array}{l}1 . \\
2 . \\
3 . \\
4 . \\
5 . \\
6 . \\
7 . \\
8 . \\
9 .\end{array}$ & $\begin{array}{l}\text { D. B. } \\
\text { J. M. } \\
\text { L. D. } \\
\text { J. M. } \\
\text { F. T. } \\
\text { R. D. } \\
\text { G. O. } \\
\text { G. B. } \\
\text { B. G. }\end{array}$ & $\begin{array}{l}82 \\
36 \\
15 \\
64 \\
26 \\
48 \\
58 \\
25\end{array}$ & $\begin{array}{l}\text { Fulminating pneumonia } \\
\text { ", } \\
\text { Lung abscess } \\
\text { Pneumonia } \\
\text { ", } \\
\text { ", } \\
\text { Staphylococcal plastic bronchitis }\end{array}$ & $\begin{array}{l}\text { N.T. } \\
\text { N.T. } \\
\circ \\
0 \\
128 \\
128 \\
\text { N.T. } \\
128 \\
128\end{array}$ & $\begin{array}{r}1 \\
4 \\
1 \\
6 \mathrm{I} \\
35 \\
14 \\
27 \\
21 \\
32\end{array}$ & $\begin{array}{l}\text { Died } \\
\text { ", } \\
\text {," } \\
\text { Recovered } \\
\text {," } \\
\text {," }\end{array}$ \\
\hline
\end{tabular}

TABLE 7

Tuberculosis During Influenza Epidemic

\begin{tabular}{|c|c|c|c|c|c|c|}
\hline & Case & Age & Diagnosis & $\begin{array}{l}\text { C.F. } \\
\text { Titre }\end{array}$ & $\begin{array}{l}\text { Duration } \\
\text { of Stay } \\
\text { (Days) }\end{array}$ & Result \\
\hline $\begin{array}{l}\text { I. } \\
2 . \\
3 . \\
4 . \\
5 .\end{array}$ & $\begin{array}{l}\text { J. J. } \\
\text { A. A. } \\
\text { G. H. } \\
\text { H. A.(P) } \\
\text { E. P. }\end{array}$ & $\begin{array}{l}73 \\
59 \\
69 \\
45 \\
69\end{array}$ & $\begin{array}{l}\text { Tub. bronchopneumonia (autopsy) } \\
\text { Tub. bronchopneumonia (positive sputum) } \\
\text { Tub. bronchopneumonia (positive sputum) } \\
\text { Chronic pulmonary Tub. (radiological) } \\
\text { Chronic pulmonary Tub. (radiological) }\end{array}$ & $\begin{array}{r}64 \\
\circ \\
64 \\
64 \\
32\end{array}$ & $\begin{array}{l}25 \\
32 \\
29 \\
14 \\
21\end{array}$ & 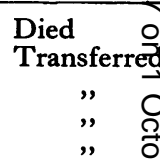 \\
\hline
\end{tabular}

was the proved or presumed cause of respiratory complication of influenza. Three other patients with proved or presumed staphylococcal infection from whom no sera were obtained were included in the study. Details of these 9 patients are classified in Table 6 .

There were three male patients with fulminating pneumonia, aged 82,36 and 15 years respectively. In only one of these was there a history of previous respiratory disease. Each patient was admitted within 48 hours of onset; one patient died on the day of admission and two survived 3 days. In only one of these three cases did the relatives permit autopsy, which revealed the classical appearances of staphylococcal bronchopneumonia complicating influenza. Hæmorrhages had occurred into both adrenal glands. A widely sensitive staphylococcus pyogenes was cultured from the lung, and influenza $\mathrm{A} 2$ virus was cultured from the tracheal mucosa and from the lung. The remaining two fulminating cases were so similar that the diagnoses seemed beyond reasonable doubt although neither sputum nor serum was studied. Early admission after onset, cyanosis, respiratory distress and hypotension were the diagnostic features. In each ease it seemed certain that the infection was acquired before admission.

The illness of the patient dying of staphylococcal lung abcess was almost certainly influenzal in origin owing to the mode of onset and coincidence in time, although no C.F. antibody was presest in the serum. He was admitted with a bronespneumonia of the right upper lobe which shorey became confluent, cavitated, yielded Staph. pyogenes and apparently healed with prolonged antibiotic therapy. At the end of the sixth weok the patient was ready for discharge when hils fever recurred and an abscess appeared at $t \overline{\mathrm{g}} \mathrm{e}$ left apex; this seemed to be responding to antbiotic therapy when the abscess ruptured a fed caused death by flooding the bronchial tree with pus.

The sole female patient presented with $\stackrel{3}{\circ}$ staphylococcal plastic bronchitis, a complement fixation titre of $1: 128$ being obtained. A known asthmatic, she presented during the seventh month of pregnancy not with asthma but with a sevese hyperpnoa causing respiratory alkalosis, the cause being obscure until a reflex origin was indicated by the development of obstructive strid\%. Tracheostomy by Mr. D. Lloyd Davies revealed a cast the size of a small finger lying below the vocal cords; its removal was followed by the evacuation of $50 \mathrm{ml}$. of staphylococcal pus. The cast was composed of fibrin and Staph. pyogener. During the next two weeks ro similar casts we removed by bronchoscopy through the trache stomy orifice. At no time were radiologicid changes observed. The patient finally made complete recovery, was delivered at term of $\mathbb{Q}_{a}$ 
TABLE 8

Gastroduodenal Hamorrhage During Influenza Epidemic

\begin{tabular}{|c|c|c|c|c|c|c|c|}
\hline & Case & Age & $\begin{array}{c}\text { Cause of } \\
\text { Hæmorrhage }\end{array}$ & $\begin{array}{l}\text { Associated Acute } \\
\text { Respiratory Disease }\end{array}$ & $\begin{array}{c}\text { Duration } \\
\text { of Stay } \\
\text { (Days) }\end{array}$ & $\begin{array}{l}\text { C.F. } \\
\text { Titre }\end{array}$ & Outcome \\
\hline I. & H. F. & 66 & G.U. & Bronchopneumonia & 85 & $\circ$ & $\begin{array}{l}\text { Gastrectomy } \\
\text { Prostatectomy } \\
\text { Recovery }\end{array}$ \\
\hline 2. & G. S. & 48 & Aspirin. D.U. & Influenza 4 days previously & I0 & ० & Recovery \\
\hline 3. & L. L. & 71 & Aspirin. H.H. & Bronchopneumonia & 24 & 128 & Recovery \\
\hline $\begin{array}{l}4 . \\
5 .\end{array}$ & $\begin{array}{l}\text { E. S. } \\
\text { F.P. }\end{array}$ & $\begin{array}{l}69 \\
71\end{array}$ & $\begin{array}{l}\text { D.U. } \\
\text { Uncertain }\end{array}$ & $\begin{array}{l}\text { Uncertain } \\
\text { Pneumonia ro days previously }\end{array}$ & $\mathbf{I 7}$ & $\begin{array}{r}16 \\
0\end{array}$ & $\begin{array}{l}\text { Recovery } \\
\text { Died }\end{array}$ \\
\hline
\end{tabular}

healthy child, and has had little asthma since.

There were only two diagnostic features of the non-fulminating staphylococcal bronchopneumonias. Staph. pyogenes were reported from the sputum in each case, and in each case a characteristic chart was noted, the temperature, pulse and respiration rates being variably raised by 'hunting' independently. In most other respiratory infections the temperature and the pulse and respiration rates rise and fall simultaneously. It is believed that this point has not been noted previously.

\section{Pulmonary Tuberculosis}

Five male patients were admitted with disorders initially indistinguishable from influenzal bronchopneumonia but subsequently recognized as influenza complicated by pulmonary tuberculosis. A positive complement fixation reaction to high titre in four of the five cases confirmed the accuracy of the clinical assessment. Details of individual cases are shown in Table 7 .

In the first patient radiology revealed a confluent opacity in the lower part of the right upper lobe and scattered bronchopneumonic mottling elsewhere. In spite of a history of pulmonary tuberculosis Io years previously the findings were so typical of an influenzal bronchopneumonia that the diagnosis of pulmonary tuberculosis was not seriously considered. The patient rapidly became afebrile, but delayed resolution suggested a low grade staphylococcal infection, although no staphylococci were obtained from the sputum. The patient died suddenly and unexpectedly on the $25^{\text {th }}$ day of the disease. Autopsy revealed the presence of tuberculous bronchopneumonia. Thereafter Mycobacterium tuberculosis was considered among the organisms which might cause bronchopneumonia as a complication of influenza. Two more acute bronchopneumonic cases were discovered. The similarity of the illnesses in these three cases suggested that the association was not fortuitous, but that the viral infection had precipitated an acute bronchopneumonic exacerbation of a pre-existing tuberculous infection.
Two other patients were discovered in whom a diagnosis of pulmonary tuberculosis was made on clinical grounds but in whom no tubercle bacilli were recovered from the sputum, the subsequent course confirming the diagnosis in each case.

\section{Gastroduodenal Hæmorrhage}

Five male patients were admitted with this disorder during the epidemic period. These are summarized in Table 8 . Although complement fixation studies were positive in only two of these five patients, the clinical findings were strongly suggestive of recent virus infection in two other patients also. The first patient was severely ill with bronchopneumonia complicated by gastroduodenal hæmorrhage on admission. As hæmorrhage continued over the next 48 hours in spite of transfusion of ro pints of blood, gastrectomy was performed by Mr. Peter Bevan. There was a relapse of bronchopneumonia after operation; during the slow recovery retention of urine necessitated a prostatic resection. The patient was in hospital in all for 85 days but eventually showed a good recovery of respiratory function. Another patient died of a massive hæmorrhage shortly after admission. Only two patients admitted the taking of aspirin. Individual details are shown in Table 8.

\section{Klebsiella Pneumonia}

One male with pneumonia due to Klebsiella arogenes was observed during the epidemic, a complement fixation titre of $1: 128$ being obtained. The clinical appearances were typical of a Klebsiella pneumonia, namely tachypnœa, dyspnœa, cyanosis, hypotension and early cavitation. Death occurred on the fifth day.

\section{Miscellaneous}

Three male patients were placed in this group; one presented with acute paroxysmal asthma and was found to have a complement fixation titre of $\mathrm{I}: 32$; the second, an Asiatic, presented with an acute encephalitis from which he recovered 
spontaneously, complement fixation titre being I:I6; the third, also an Asiatic, presented with a severe herpes febrilis affecting the upper and lower lids of both eyes, complement fixation titre being I: 6 .

\section{Conclusions}

This study demonstrated that during the winter of $1960 / 6$ I the 'winter load' was due to acute respiratory disorders occurring as complications of influenza A (Asian). The range of these complications was wider than had been anticipated and their severity considerable.

The most frequent complications were bronchitis and bronchopneumonia. These disorders occurred only in older age groups and usually in those with previous respiratory disease. Death occurred in $20 \%$ of patients of each sex and only in those of 60 years or more. Apart from the frequent finding of widespread rales and the results of virological study there was nothing to distinguish these patients from those commonly admitted in winter regarded as suffering from exacerbation of chronic obstructive lung disease due to chronic asthma and/or bronchitis.

The next most frequent complication was staphylococcal infection. Eight males were observed with influenzal staphylococcal pneumonia of whom 4 died $(50 \%)$. One female was admitted suffering from influenzal staphylococcal plastic bronchitis, occurring during the seventh month of pregnancy; mother and fotus survived. These complications were observed scattered throughout all age groups and often in those without previous respiratory disease.

The predominant feature of the three fatal cases presenting as fulminating influenzal staphylococcal pneumonia (I proved, 2 clinical) was hypotension due to acute circulatory insufficiency. This was the cause of rapid death which was not prevented by energetic antibiotic and steroid therapy, but which was partly explained by the finding of bilateral adrenal hæmorrhage in the only fulminating case submitted to autopsy. Hers (1955) had already reported adrenal hæmorrhages in all of seven cases of influenzal staphylococcal pneumonia subjected to intensive postmortem study. He noted the absence of such hæmorrhages in non-staphylococcal influenzal deaths, concluding that the adrenal hæmorrhages were bacterio-toxic and not viro-toxic in nature. These manifestations were in fact those of the Waterhouse-Friderichsen syndrome in which the causes for the failure of treatment are not yet fully understood. Talbot (1962) discussing 'bacteræmic shock' occurring in infections due to gram-negative bacilli noted the good results that followed immediate therapy with an anti- biotic to which the organism was sensitive. staphylococcal 'bacteræmic shock' the same succe was not apparent with the three cases reported here or in other series; and the failure was certainly not due to the resistance of the staphylococci antibiotics. In one single fulminating case which autopsy study was permitted a fully senf्धु tive staphylococcus was recovered. In the sev $\overline{\bar{m}}$ cases reported by Hers (1955) and quoted above, strains of fully sensitive staphylococci weक्षe recovered from six. This finding was confirmed by Robertson, Caley and Moor, (1958), w recovered sensitive staphylococci from 12 of $\overrightarrow{\mathrm{I}} 4$ patients with fulminating influenzal staphw lococcal pneumonia dying within seven days of onset.

It is necessary to consider whether any of the infections were due to hospital cross-infection. In the three fatal fulminating cases the severify of the illnesses on admission, the early deaths and the finding of a fully sensitive staphylococcus in the one case where an organism was recovered, \&l suggest that infection occurred before admission. Of the six non-fulminating cases, fully sensitiqe staphylococci were recovered from three on tfige second day of admission and from one on the sixth day. In seven of nine cases, therefore, there are grounds for concluding that infection ows acquired before admission. In the remainifity two patients cross-infection cannot be excludeg; in one who survived, a strain of Staph. pyogeres was recovered on the ninth day, sensitive to chloramphenicol and novobiocin only; in the oth who succumbed from the rupture of a staphlococcal lung abscess, a strain of Staph. pyogents insensitive to penicillin, tetraycline and erythromycin was obtained. The high mortality, tbe sensitivity of many of the staphylococci and the evidence in favour of the acquisition of infection before admission have been reported previous $\mathrm{k}$. Robertson and others (1958) noted the hig mortality $(47 \%)$ in patients affected with staph lococcal infections in the influenza $\mathrm{A} 2$ epidemic of 1957 in Sheffield, and observed that this applied equally to those patients with sensitive straigs acquired before admission, and to those with insensitive strains, not all of which were cleary acquired after admission.

The finding of 3 proved and 2 clinical cases of pulmonary tuberculosis complicating influenæa was disturbing. In the first case the sputum was not examined for tubercle bacilli as pulmona tuberculosis was not suspected; the diagnosis was made at autopsy. In the second case tuberche bacilli were noted only after sputum culture and by the time this was reported the patient was इ5 ill as to appear moribund, although in fact a slow recovery followed the institution of specifice 
therapy. This diagnosis would not have been made without the experience provided by the first case. In the two clincial cases radiology revealed bilateral apical opacities typical of pulmonary tuberculosis of low grade activity. The virus infection had apparently done no more than provide a reason for the radiology that revealed the presence of tuberculous lesions. But in the three other cases an acute tuberculous bronchopneumonia was present which appeared to have been aggravated by the viral infection. In these patients the clinical and radiological appearances were indistinguishable from those of influenzal staphylococcal bronchopneumonia although the characteristic temperature chart of the latter condition was lacking. This difficulty in distinguishing between pyogenic and tuberculous bronchopneumonia complicating influenza was noted by Rich (1944) who, discussed the possible relationship between influenza and exacerbation of tuberculosis without reaching any conclusion. Certainly in the five cases reported here positive evidence of influenza was present in four and the observation of three cases of bronchopneumonic tuberculosis during the course of the epidemic strongly suggested a relationship, since it had become exceptional by 1960 to observe three such cases in so short a period.

The finding of preceding respiratory infection in four of five patients with gastroduodenal hæmorrhage, with C.F. studies positive in two of these, is of importance not only in relation to aspirin therapy, which was a final cause of hæmorrhage in two cases and a possible cause in two others, but the preceding respiratory infection is a severe hazard if gastrectomy proves necessary, as it did in one case reported here.

Finally, it is noteworthy that with the exception of 20 cases of influenzal bronchitis and bronchopneumonia and one case of stapylococcal bronchitis, all the complicated cases occurred in males. This suggests that a study of the smoking habits of patients admitted for complications of influenza in future epidemics would be desirable.

I am indebted to Dr. T. H. Flewett for his meticulous - virological studies and for his critical advice; to Dr. W. D. Foster for his bacteriological studies; to Dr. I. S. Buchanan for his permission to include some of his cases in this study, and to my house physicians and ward sisters, whose enthusiastic collaboration made this study possible.

\section{REFERENCES}

Clarke, S. K. R., Heath, R. B., Sutton, R. N. P., and Stuart-Harris, C. H. (1958): Serological Studies with Asian

Strain of Influenza A, Lancet, i, 814 .
Hers, J. F. PH. (I955): 'Histopathology of the Respiratory Tract in Human Influenza'. Leiden: H. E. Stenfert Kroese N.V.

Rich, A. R. (1944): 'Pathogenesis of Tuberculosis'. Springfield, Illinois: Charles C Thomas.

Robertson, L., Caley, J. P., and Moore, J. (1958): Importance of Staphylococcus aureus in Pneumonia in the 1957 Epidemics of Influenza A, Lancet, ii, 233.

Stuart-HarRis, C. H. (I953): 'Influenza and other Infections of the Respiratory Tract'. London: Edward Arnold.

Talbot, C. H. (1962): Septicæmia Due to Gram Negative Bacilli, Lancet, i, 668. 